\title{
Transrectal ultrasound study of the pathogenesis of solitary rectal ulcer syndrome
}

\author{
M J Van Outryve, P A Pelckmans, H Fierens, Y M Van Maercke
}

\begin{abstract}
Transrectal ultrasonography is of clinical value in anorectal carcinoma and in inflammatory diseases of the anorectum. In this study a rigid linear endorectal probe was used to examine 15 patients with endoscopically and biopsy proved diagnosis of solitary rectal ulcer syndrome. In 13 of the 15 patients the rectal wall was thicker (mean (SEM) 5.7 (0.4) mm; normal values: $2 \cdot 8(0 \cdot 1) \mathrm{mm})$ near the rectal ulcer. In all these cases the muscularis propia layer exceeded the maximum normal diameter of $2 \mathrm{~mm}$. In nine of the 15 patients the normal rectal wall echostructure, with five distinct layers, was disturbed and there was fading of the borders between the mucosa and the muscularis propria. Poor relaxation of the puborectalis muscle during straining was seen on ultrasound in 11 patients, as was intussusception of the rectal wall. The obvious enlargement of the muscularis propria points to a chronic mechanical load on the rectal wall. The ulcerative lesions are formed in this area of overloaded rectal wall. The direct visualisation of the puborectalis muscle during dynamic transrectal ultrasonography indicates that the fact that it does not relax is an important element in the pathogenesis of solitary rectal ulcer syndrome.

(Gut 1993; 34: 1422-1426)
\end{abstract}

Solitary rectal ulcer syndrome is a remarkable entity, the diagnosis of which has to be differentiated from inflammatory bowel disease or other forms of proctitis. The name solitary rectal ulcer is misleading because there can be more than one ulcer and at a stage of the disease no ulceration is present.

The aetiopathogenesis of the syndrome has been elucidated recently with the help of defecography ${ }^{12}$ and other functional anorectal examinations. ${ }^{3-6}$ The ulceration is probably provoked by mucosal prolapse and intussusception during excessive straining at stool, with chronically repeated mucosal trauma and ischaemia. ${ }^{7}$ Ruptures of submucosal vessels and obliteration of mucosal capillaries by fibrous tissue in the lamina propria are described. ${ }^{89}$ The excessive straining is seen as an attempt to overcome the inappropriate contraction of the puborectalis muscle $^{5}$ or as a result of hypersensitivity of the rectum. ${ }^{10}$

Sigmoidoscopy shows that the (ulcerative) lesions are mostly located at the anterior or anterolateral wall of the rectum. They vary in size and in shape and are located $4-10 \mathrm{~cm}$ from the anal verge. In about a third of the cases there is no ulcer, ${ }^{9}$ but a mild proctitis with fiery red and thickened nodular folds, excessive mucus secretion, and mucosal friability. ${ }^{8}$

Histopathology is mandatory for the diagnosis and shows a typical obliteration of the lamina propria by fibrosis and smooth muscle fibres extending from a thickened muscularis mucosa towards the lumen. ${ }^{7-9}$ There is often distortion of the crypt architecture. The ulcers are always superficial and never penetrate beneath the submucosa. In resection specimens, fibrosis of the submucosa and thickening of the muscularis propria are also found..$^{7-11}$ In a minority of cases, glands are displaced in the submucosa where they may become cystically dilated, the so called 'colitis cystica profounda'. 9 This is considered to be a variant of the solitary rectal ulcer syndrome with the same pathogenesis as the solitary rectal ulcer itself. ${ }^{11}$

Transrectal ultrasonography is easy to perform, well tolerated, and can be repeated as a follow up examination. Its value is proved in the staging and follow up of anorectal carcinoma, ${ }^{12} 13$ and it is increasingly used in inflammatory diseases of the anorectum. ${ }^{14}$ is In solitary rectal ulcer syndrome, transrectal ultrasonography should clearly delineate the rectal wall and its separate layers. Mucosal ulcerations and changes in the rectal wall architecture should be easily detected and eventually measured. Dynamic examination should allow a study of the puborectalis muscle and the anal sphincter, especially during defecation. Indeed, previous studies clearly visualised the anal sphincter and the puborectalis muscle. ${ }^{15} 16-18$ Transrectal ultrasonography of the puborectalis muscle during straining should help to elucidate the complex pathogenesis of the solitary rectal ulcer syndrome.

\section{Methods}

\section{PATIENTS}

The study concerns 15 consecutive patients with solitary rectal ulcer syndrome. There were 12 women and three men (mean age 39.6 years, range 19-68 years) with endoscopically and biopsy proved solitary rectal ulcer syndrome. In 13 patients, sigmoidoscopy showed a distinct ulcer, located typically on the anterior or the anterolateral rectal wall $4-10 \mathrm{~cm}$ from the anal verge. In the two remaining patients erythematous mucosal folds with intraluminal mucus hypersecretion and mucosal friability were found. The typical histological criteria ${ }^{7}$ of fibrosis and muscular obliteration of the lamina propria, with enlargement of the muscularis mucosae, were fulfilled in all cases. Colitis cystica profunda was not seen. All patients had a history 
of several years of vigorous straining at stool, with a sensation of incomplete rectal discharge.

\section{TECHNIQUE}

Transrectal ultrasound examination was performed with a rigid linear endorectal probe (model IVV5060; Toshiba, Tokyo, Japan) by the same investigator (MVO), and the scans were discussed with the other authors. A linear endorectal probe was used, since this provided clear images of the rectal wall layers, the perirectal and pelvic floor structures, and the anal sphincter. ${ }^{15}$ The frequency of the ultrasound waves was $5 \mathrm{MHz}$. The patients were placed in the left lateral decubitus. A water filled balloon at the top of the probe served as an acoustic window for the ultrasonic beams. The examination was performed by rotating the probe through $360^{\circ}$.

\section{VARIABLES EXAMINED}

\section{Morphology of the rectal wall}

The entire rectal wall consists of five layers. ${ }^{12} 19$ The mucosa is defined as the hypo-echoic layer nearest the balloon and the muscularis propria as the outermost hypo-echoic layer. The three remaining hyper-echoic layers are considered as interfaces. Normally, the individual layers are
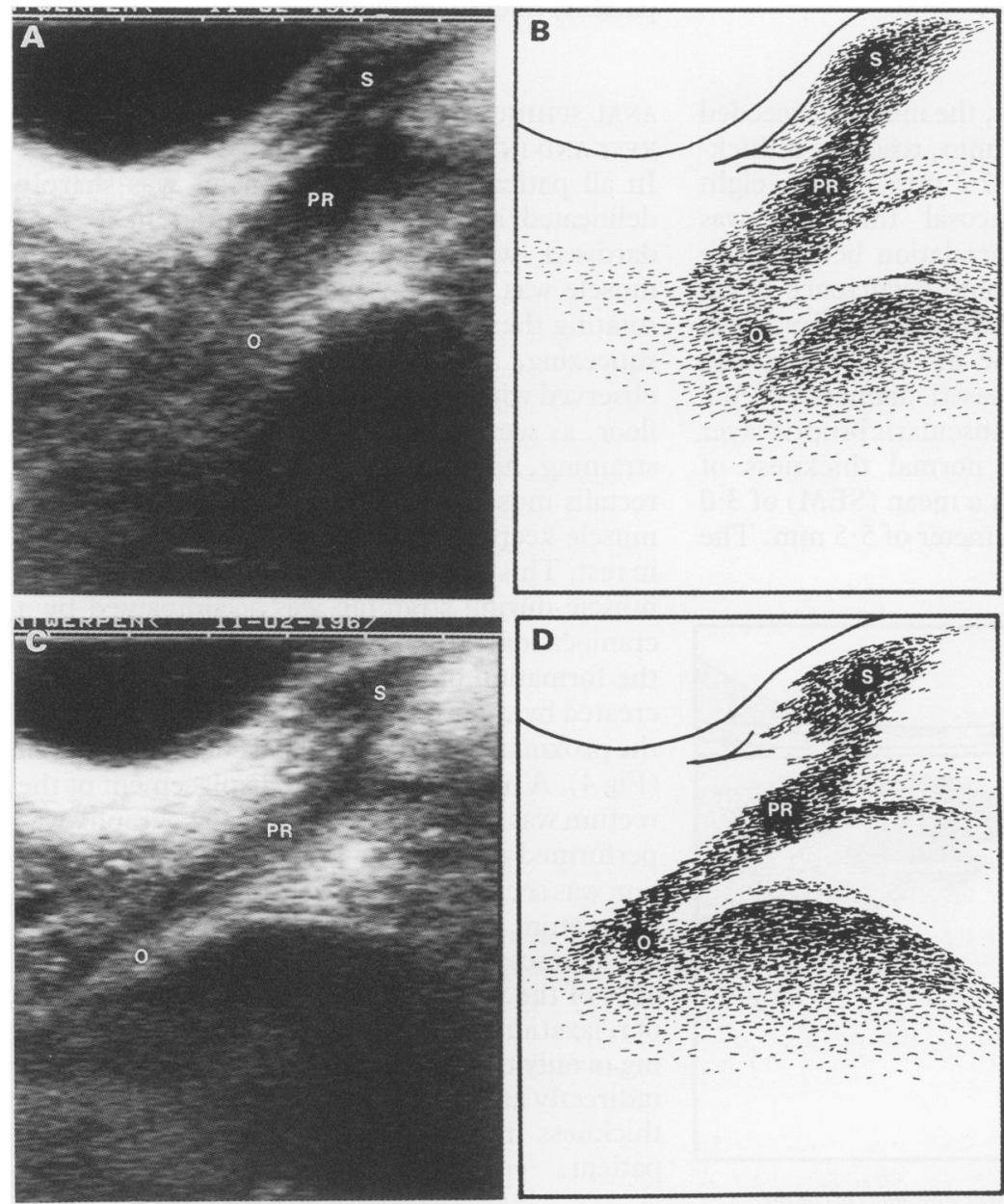

Figure 1: Longitudinal transrectal ultrasound scan $(A$ and $C)$ and schematic drawings $(B$ and $D)$ of the anal sphincter $(S)$ and puborectalis muscle $(P R)$ at rest $(A-B)$ and during straining $(C-D)$. The puborectalis muscle arises from the pubic bone $(O)$ and forms a functional entity with the external component of the anal sphincter, both moving distally during straining. clearly distinct from each other and are not interrupted. An ulcer is characterised as an echorich spot or zone that interrupts the continuity of the layer. Fading of the borders between the individual layers is not seen in healthy individuals and can be considered as abnormal.

\section{Rectal wall thickness}

According to the published reports and to our previous studies in normal subjects, ${ }^{15}$ a maximum thickness of $1 \mathrm{~mm}$ for the mucosa and of $2 \mathrm{~mm}$ for the muscularis propria are considered normal, with a maximum thickness of $4 \mathrm{~mm}$ for the entire rectal wall. ${ }^{20-22}$ In a preliminary study of 40 normal subjects, ${ }^{15}$ the mean thickness of the muscularis propria was $1.0 \mathrm{~mm}$ and the mean thickness of the entire rectal wall $2 \cdot 8 \mathrm{~mm}$. Using exactly the same technique, the thickness of the mucosa, the muscularis propria, and the total rectal wall were measured in all 15 patients with solitary rectal ulcer syndrome.

\section{Anal sphincter and puborectalis muscle at rest and in} dynamic conditions

The anal sphincter originates from the rectal muscular layer as a sharply delineated ellipsoid area. The internal component of the sphincter is quite homogeneous and echo-poor, the external component is more echo-rich (Fig 1A-B). The length and breadth of the sphincter can easily be measured. Length was defined as the largest craniocaudal diameter and breadth as the largest ventrodorsal diameter, both expressed in $\mathrm{mm} .{ }^{15}$ The puborectalis muscle was defined as the central part of the levator ani muscle, originating from the pubic bone and joining the external component of the anal sphincter. The anal sphincter and the puborectalis muscle were examined at rest, during voluntary contraction of the sphincter (squeezing), and during defecation movement (straining). A previous study in healthy individuals showed a decrease in length and an increase in breadth of the anal sphincter during squeezing. ${ }^{15}$ At the mean time, a contraction of the puborectalis muscle with an upward movement of the pelvic floor was observed. During straining the anal sphincter increased in length and decreased in breadth. The puborectalis muscle relaxed and became longer and smaller, moving distally as a functional entity with the anal sphincter (Fig 1C and D).

\section{STATISTICS}

All data are expressed as mean (SEM). The statistical analysis was performed with the Wilcoxon's rank sum test. p values $<0.05$ were considered significant.

\section{Results}

MORPHOLOGY OF THE RECTAL WALL

An ultrasound scan typical of ulceration was detected in eight of the 13 patients with an ulcer seen at sigmoidoscopy. At transrectal ultrasonography the ulcer was always superficial and restricted to the mucosal layer (Fig 2). In nine of 

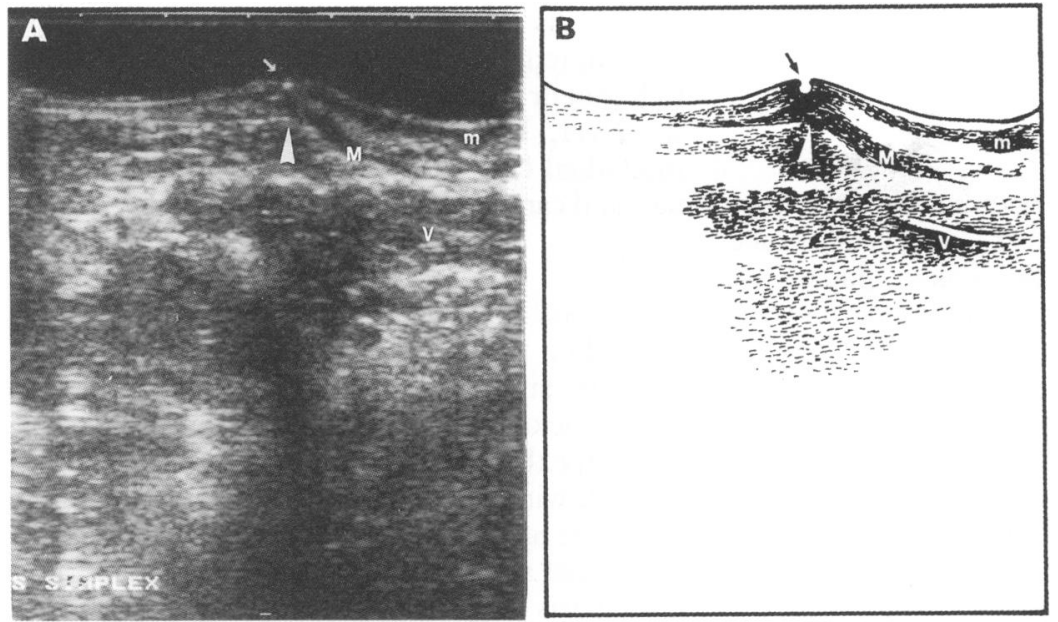

Figure 2: Longitudinal transrectal ultrasound scan $(A)$ and schematic drawing $(B)$ of the rectal wall in a patient with solitary rectal ulcer syndrome. Note the mucosal ulceration (arrow), the mucosa $(m)$, the muscularis propria $(M)$ and the vagina $(V)$. The rectal wall layers merge into each other in the vicinity of the ulcer (arrowhead).

the 15 patients, the characteristic five layered structure of the rectal wall was disrupted. In these cases, the borders of the mucosa and muscularis propria layers faded in the immediate vicinity of the ulcer (Fig 3). A noticeable enlargement of the muscularis propria was often observed, bridging towards the mucosa with merging of the two layers. Cystic dilatations in one or more of the layers were not encountered.

\section{RECTAL WALL THICKNESS}

In seven of the 15 patients, the mucosa exceeded the normal thickness of $1 \mathrm{~mm}$, reaching a thickness of $2-2 \cdot 5 \mathrm{~mm}$ (mean $2 \cdot 2 \mathrm{~mm}$ ). In the eight other patients, the mucosal thickness was normal. There was no correlation between the sigmoidoscopic or ultrasonic occurrence of an ulcer and the thickness of the mucosal layer. An increased thickness of the mucosa was always accompanied by an increased diameter of the muscularis propria. The muscularis propria layer exceeded the maximum normal thickness of $2 \mathrm{~mm}$ in 13 patients, with a mean (SEM) of 3.0 $(0.3) \mathrm{mm}$ and a largest diameter of $5.5 \mathrm{~mm}$. The
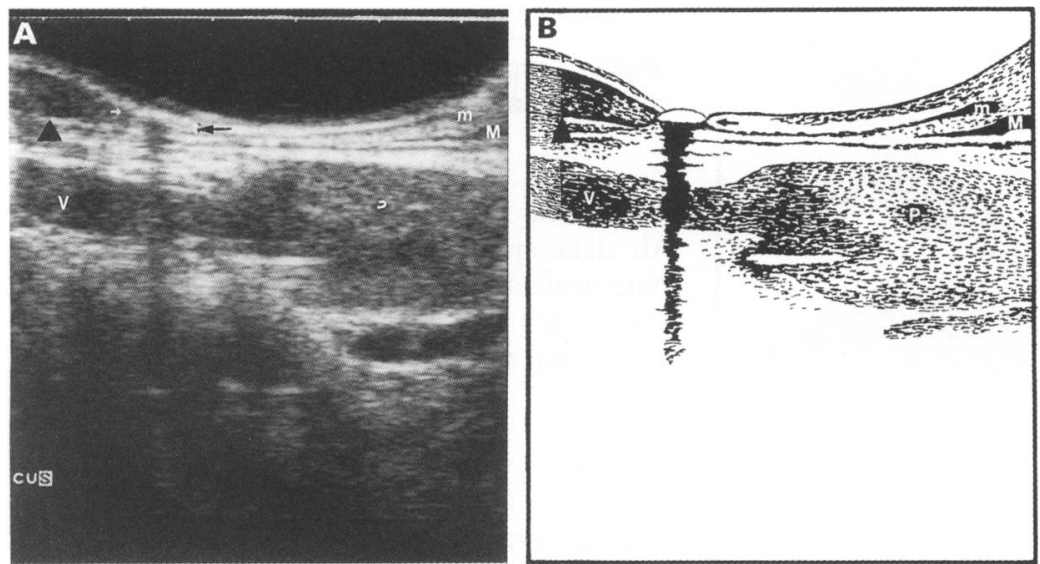

Figure 3: Longitudinal transrectal ultrasound scan $(A)$ and schematic drawing $(B)$ of the rectal wall in a patient with solitary rectal ulcer syndrome. Note the mucosal ulceration (arrows), the mucosa $(m)$, the muscularis propria $(M)$, the seminal vesicle $(V)$ and prostate gland $(P)$. The typical five layered rectal wall structure has disappeared proximally to the ulcer (arrowhead).
TABLE I Rectal wall dimensions in solitary rectal ulcer syndrome patients compared with normal values

\begin{tabular}{llll}
\hline & No & $\begin{array}{l}\text { Muscularis } \\
\text { propria }(\mathrm{mm})\end{array}$ & $\begin{array}{l}\text { Entire rectal } \\
\text { wall }(\mathrm{mm})\end{array}$ \\
\hline Normal subjects & 40 & $1 \cdot 0(0 \cdot 1)$ & $2 \cdot 8(0 \cdot 1)$ \\
Patients & 15 & $3 \cdot 0(0 \cdot 3)^{\star}$ & $5 \cdot 7(0 \cdot 4)^{\star}$ \\
\hline
\end{tabular}

Values are mean (SEM).

$\star$ Significantly different from values in normal subjects $(\mathrm{p}<0.0001)$.

TABLE II Anal sphincter dimensions in 15 patients with solitary rectal ulcer syndrome

\begin{tabular}{lll}
\hline & $\begin{array}{l}\text { Length } \\
(\mathrm{mm})\end{array}$ & $\begin{array}{l}\text { Breadth } \\
(\mathrm{mm})\end{array}$ \\
\hline Rest & $34 \cdot 2(1 \cdot 8)$ & $6 \cdot 4(0 \cdot 5)$ \\
Squeezing & $32 \cdot 3(1 \cdot 8)^{\star}$ & $6 \cdot 4(0 \cdot 5)$ \\
Straining & $34 \cdot 1(1 \cdot 7)$ & $5 \cdot 3(0 \cdot 4) \dagger$ \\
\hline
\end{tabular}

Values are mean (SEM)

$\star$ Significantly different from length at rest $(p<0.025)$.

+ Significantly different from breadth at rest $(p<0 \cdot 004)$.

enlarged area was generally irregular, but with a maximal thickness in the immediate vicinity of the ulcer (Fig 2). The entire rectal wall thickness was increased in 13 patients with a mean (SEM) of $5 \cdot 7(0.4) \mathrm{mm}$ for the 15 patients and a maximal thickness of $8.0 \mathrm{~mm}$. In all these patients the muscularis propria was enlarged, in eight of them the mucosal layer was enlarged too. The thickness of the muscularis propria and of the total rectal wall was significantly larger in these patients than in normal subjects (Table I).

\section{ANAL SPHINCTER AND PUBORECTALIS MUSCLE AT} REST AND IN DYNAMIC CONDITIONS

In all patients, the anal sphincter was sharply delineated and could be measured in a standardised way (Table II). The puborectalis muscle was clearly visualised in all patients by rotating the probe in a lateral direction. During squeezing, contraction of the muscle was observed with an upward movement of the pelvic floor, as seen in all healthy individuals. During straining, however, poor relaxation of the puborectalis muscle was observed in 11 patients; the muscle keeping an identical morphology to that in rest. This lack of relaxation of the puborectalis muscle during straining was accompanied by a craniocaudal intussusception of the rectum, with the formation of a typical 'onion like' structure created by superposition of the different layers of the proximal unto the distal part of the rectal wall (Fig 4). A noticeable ventral displacement of the rectum was seen in 10 cases. A defecography was performed in 13 of our 15 patients. Intussusception was seen in $61 \%$ and ventral displacement of the rectum in $76 \%$. An insufficient widening of the anorectal angle at straining was observed in $41 \%$ of the patients. Defecography showed lack of relaxation of the puborectalis muscle at straining in only two cases, but this muscle was viewed indirectly at the dorsal side of the rectum. A full thickness rectal prolapse was noted in one patient.

\section{Discussion}

Our patient group can be considered as repre- 

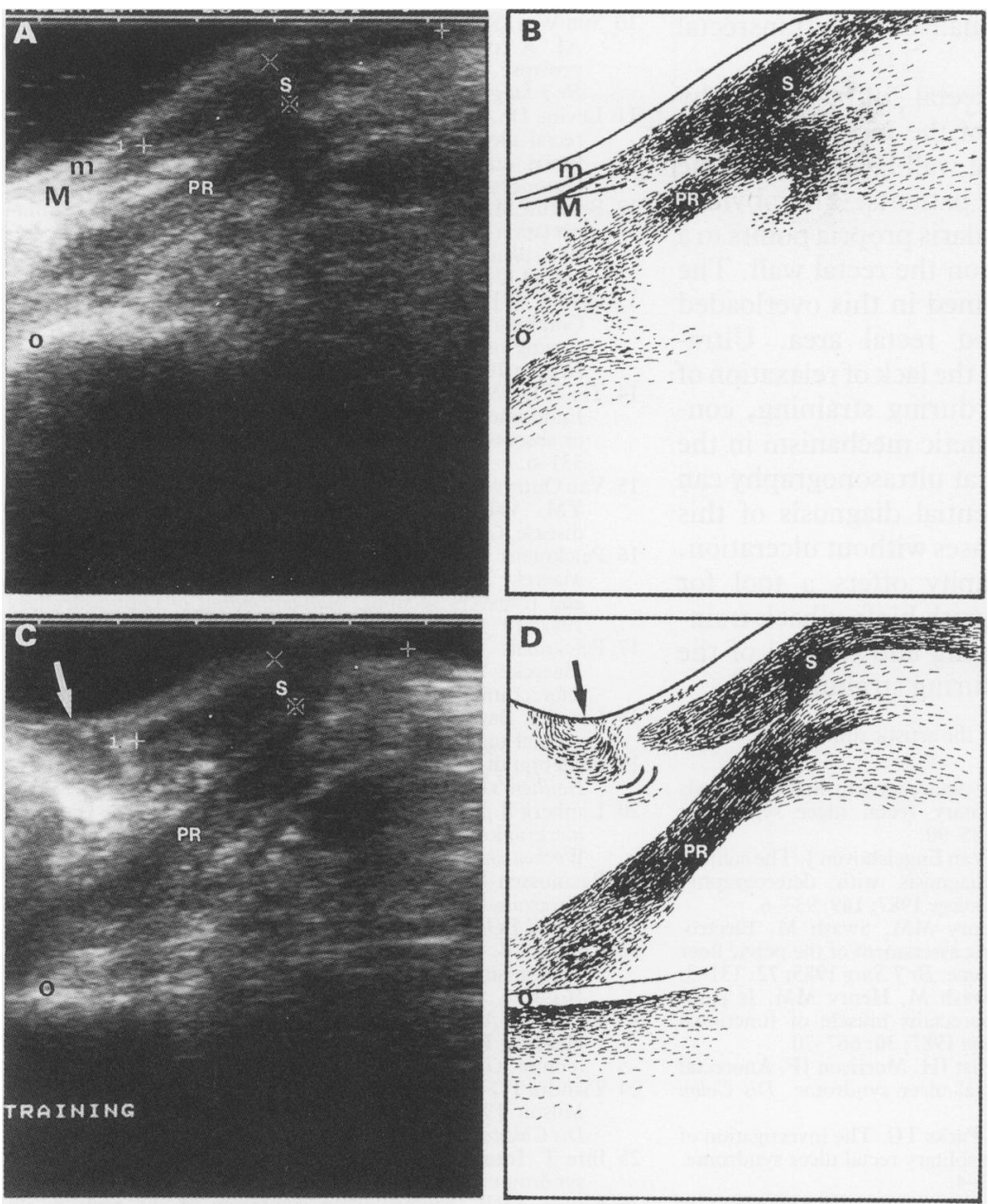

Figure 4: Longitudinal transrectal ultrasound scans $(A$ and $C$ ) and schematic drawings ( $B$ and $D)$ of the anal sphincter $(S)$ and puborectalis muscle $(P R)$ at rest $(A-B)$ and during straining $(C-D)$. Constant morphology and dimensions of the puborectalis muscle during straining, compared with at rest. Ventral movement of the rectum and pelvic floor with rectal intussusception (arrow) during straining. Note the mucosa $(m)$, the muscularis propria $(M)$ and the pubic bone $(O)$. side of the rectum during straining, is indirect and often hard to evaluate. The direct visualisation of the puborectalis muscle during dynamic transrectal ultrasonography examination indicates that the lack of relaxation of this pelvic floor muscle is an important element in solitary rectal ulcer syndrome pathogenesis.

When the puborectalis muscle does not relax sufficiently at straining, the anal canal is not brought into the same axis as the rectum and faecal expulsion is inhibited. This leads to excessive and repeated straining. In our study the ulcers are located in the area of increased thickness of the muscularis propria. This suggests that the ulceration occurs in the zone of the highest muscular activity. Manometric studies showed a high intrarectal pressure in these patients. ${ }^{5}$ Anal electromyographic studies showed sustained pelvic floor muscle activity in these patients during straining. ${ }^{34}$

Our transrectal ultrasonography showed a statistically significant increase in the thickness of the muscularis propria and in the total rectal wall thickness when compared with the results in our normal subjects. ${ }^{15}$ The increase in rectal wall thickness was mainly due to an enlargement of the muscularis propria layer; an enlargement of the mucosal layer only occurred in $46 \%$ of the patients. Routine sigmoidoscopic biopsy specimens are superficial and restricted to the mucosa and muscularis mucosae, the muscularis propria is absent. Surgical resection specimens, however, confirm the enlargement of the muscularis propria in this syndrome. ${ }^{711}$

Interestingly, an increased thickness of the total rectal wall was also observed in inflammatory bowel disease, in $58 \%$ of patients with active Crohn's disease, ${ }^{15}$ strikingly more than the proportion in ulcerative colitis. ${ }^{21}$ This reflects the transmural inflammation and fibrosis in Crohn's disease. In solitary rectal ulcer syndrome the increased rectal wall thickness could also be provoked by chronic inflammation, oedema, and fibrosis in addition to the muscular factors mentioned above. The chronic inflammation of the mucosa, with fibrosis of the lamina propria and extension of smooth muscle fibres from the muscularis mucosae to the lamina propria, was confirmed histologically in all our patients. This explains the distortion of normal rectal wall architecture on ultrasonography.

In our patients we could not detect anomalies in the morphology of the anal sphincter. The dimensions at rest, during squeezing, and straining (although individually variable), were similar to those observed in healthy individuals. ${ }^{\text {is }}$ This argues against a primary dysfunction of the anal sphincter itself in the pathogenesis of this disorder. As expected ultrasonography was less effective than sigmoidoscopy in visualising superficial mucosal ulcers. The use of higher frequency probes $(7 \cdot 5$ and $12 \mathrm{MHz})$ should facilitate the diagnosis of superficial mucosal defects. ${ }^{14}$ However, $5 \mathrm{mHz}$ probes allow excellent imaging of the pelvic floor structures, especially of the puborectalis muscle. There are no cases of colitis cystica profunda in our series. In solitary rectal ulcer syndrome well delineated cystic lesions that did not penetrate beyond the submucosa and were well differentiated from 
rectal carcinoma were visualised with transrectal ultrasonography. ${ }^{27}$

In conclusion, transrectal ultrasonography allowed a precise study of the morphology and the thickness of the rectal wall layers and of the anal sphincter in all our patients. The obvious enlargement of the muscularis propria points to a chronic mechanical load on the rectal wall. The ulcerative lesions are formed in this overloaded and chronically inflamed rectal area. Ultrasonography clearly shows the lack of relaxation of the puborectalis muscle during straining, confirming this as a pathogenetic mechanism in the syndrome. We suggest that ultrasonography can be helpful in the differential diagnosis of this syndrome, especially in cases without ulceration. Transrectal ultrasonography offers a tool for more accurate treatment with biofeedback training, allowing direct imaging and control of the pelvic floor movements during straining.

The authors thank Anita Muys for the artistic drawings.

1 Mahieu PH. Barium enema and defaecography in the diagnosis and evaluation of the solitary recta Int 7 Colorectal Dis 1986; 1: 85-90.

2 Goei R, Baeten C, Janevski B, Van Engelshoven J. The solitary rectal ulcer syndrome: diagnosis with defecography. American fournal of Roentgenology 1987; 149: 933-6.

3 Snooks SJ, Nicholls RJ, Henry MM, Swash M. Electrophysiological and manometric assessment of the pelvic floor physiological and manometric assessment of the pelvic floor

4 Jones PN, Lubowski DZ, Swash M, Henry MM. Is paraJones PN, Lubowski DZ, Swash M, Henry MM. Is para-
doxical contraction of puborectalis muscle of functional importance? Dis Colon Rectum 1987; 30: 667-70.

5 Womack NR, Williams NS, Mist JH, Morrison JF. Anorecta function in the solitary rectal ulcer syndrome. Dis Colo Rectum 1987; 30: 319-23.

6 Mackle EJ, Manton Mills JO, Parks TG. The investigation of anorectal dysfunction in the solitary rectal ulcer syndrome. Int 7 Colorect Dis 1990; 5: 21-4.

7 Madigan MR, Morson BC. Solitary ulcer of the rectum. Gut 1969; 10: 871-81.

8 Fenoglio-Preiser CM, Lantz PE, Listrom MB, Davis M, Rilke FO. Gastrointestinal pathology. An atlas and text. New York: Raven Press, 1989.

9 Goldman H, Appelman H, Kaufman N. Gastrointestinal pathology. Baltimore: Williams \& Wilkins, 1990
10 Sun WM, Read NW, Donnelly TC, Bannister JJ, Shorthouse AJ. A common pathophysiology for full thickness recta prolapse, anterior mucosal prolapse and solitary rectal ulcer. BrF Surg 1989; 76: 290-5.

11 Levine DS. "Solitary" rectal ulcer syndrome. Are "solitary" rectal ulcer syndrome and "localized" colitis cystica profunda analogous syndromes caused by rectal prolapse? Gastroenterology 1987; 92: 243-53.

12 Boscaini M, Montori A. Transrectal Ultrasonography: interpretation of normal intestinal wall structure for the preoperapretation of normal intestinal wall structure for the preopera-
tive staging of rectal cancer. Scand $\mathcal{F}$ Gastroenterol 1986; 21 (suppl 123): 87-98

13 Orrom WJ, Wong WD, Rothenberger DA, Jensen LL, Goldberg SM. Endorectal ultrasound in the preoperative staging of rectal tumors: a learning experience. Dis Colon Rectum 1990; 33: 654-60

14 Tio TL, Mulder CJ, Wijers OB, Sars PR, Tytgat GN Endosonography of peri-anal and pericolorectal fistula and or abscess in Crohn's disease. Gastrointest Endosc 1990; 36 : $331-6$.

15 Van Outryve MJ, Pelckmans PP, Michielsen PP, Van Maercke YM. Value of transrectal ultrasonography in Crohn's disease. Gastroenterology 1991; 101: 1171-7.

16 Pelckmans PA, Van Outryve MJ, Michielsen PP, Van Maercke YM. Endosonography of the rectum: longitudinal and transvers sections. Italian foumal of Gastroenterology and transvers sections.

17 Pelckmans PA, Van Outryve MJ, Michielsen PP, Van Maercke YM. Endosonography of the anal sphincter and anorectum. Gastroenterology 1988; 94: A348.

18 Law PJ, Bartram CL. Anal endosonography: technique and normal anatomy. Gastrointest Radiol 1989; 14: 349-53.

19 Hildebrandt U, Feifel G, Ecker KW. Rectal endosonography. Baillière's Clin Gastroenterol 1989; 3: 531-41.

20 Limberg B. Differentialdiagnose akut entzündlicher Dickdarmerkrankungen durch Kolonsonographie. Dtsch Med Wochenschr 1987; 112: 382-5.

21 Rasmussen SN, Riis P, Rectal wall thickness measured by ultrasound in chronic inflammatory diseases of the colon. ultrasound in chronic inflammatory dise

22 Limberg B. Sonographic features of colonic Crohn's disease: comparison of in vivo and in vitro studies. $\mathcal{F C U} 1990 ; 18$ compa $161-6$.

23 Ford MJ, Anderson JR, Gilmour HM, Hold S, Sircus W, Heading RC. Clinical spectrum of "solitary ulcer" of the rectum. Gastroenterology 1983; 84: 1533-40

24 Tjandra JJ, Fazzio VW, Church JM, Lavery IC, Oakley JR, Milson JW. Clinical conundrum of solitary rectal ulcer. Dis Colon Rectum 1992; 35: 227-35.

25 Ihre $T$. Intussusception of the rectum and the solitary ulce syndrome. Ann Med 1990; 22: 419-23.

26 Rutter KRP. Solitary ulcer syndrome of the rectum: its relation to mucosal prolapse. In: Henry MM, Swash M, eds. Coloproctology and the pelvic floor. Pathophysiology and manColoproctology and the pelvic floor. Pathophysiol
agement. London: Butterworth, 1985, 282-98.

27 Hulsmans FJ, Tio TL, Reeders JW, Tytgat GN. Transrectal US in the diagnosis of localized colitis cystica profunda. Radiology 1991; 181: 201-3. 